\title{
Future Deltas Utrecht University research focus area: towards sustainable management of sinking deltas
}

\author{
E. Stouthamer and S. van Asselen \\ Dept. of Physical Geography, Faculty of Geosciences, Utrecht University, Utrecht, the Netherlands \\ Correspondence to: E. Stouthamer (e.stouthamer@uu.nl)
}

Published: 12 November 2015

\begin{abstract}
Deltas are increasingly under pressure from human impact and climate change. To deal with these pressures that threat future delta functioning, we need to understand interactions between physical, biological, chemical and social processes in deltas. This requires an integrated approach, in which knowledge on natural system functioning is combined with knowledge on spatial planning, land and water governance and legislative frameworks. In the research focus area Future Deltas of Utrecht University an interdisciplinary team from different research groups therefore works together. This allows developing integrated sustainable and resilient delta management strategies, which is urgently needed to prevent loss of vital delta services.
\end{abstract}

\section{Introduction}

Deltas are valuable but vulnerable areas (e.g. Syvitski, 2008; Vörösmarty et al., 2009; Giosan et al., 2014). They provide essential services to humans, such as fertile land for food production, biodiversity, drinking and irrigation water and a river network for transportation. Because of all these benefits, over 500 million people live in deltas worldwide. These people are however increasingly under pressure of human and climate change, introducing impacts of different nature: sea-level rise, land subsidence, ecosystem degradation, increasing flood risk, pollution, loss of biodiversity, conflicting land claims and declining livability. To find solutions for sustainable management of deltas under pressure, the research focus area Future Deltas has been established (2014-2017). Every four years, Utrecht University defines new research focus areas to stimulate interdisciplinary research, that should act as nuclei for broad (inter)national collaborations.

Future Deltas aims to understand and predict how deltas under pressure of massive urbanization, land-use and climate change, sea level rise and subsidence will change in the future and how societies can successfully deal with this. To be able to predict and anticipate to the impacts of these changes in future deltas, it is crucial to have insight and profound understanding of the functioning of both natural and societal aspects of delta systems. This enables us to answer questions like: how does river embankment influence floodplain development and coastal sedimentation? What is the impact of deep and shallow groundwater extraction due to expanding cities on subsidence and saltwater intrusion? Who is responsible for causes of negative impacts, how are mitigation strategies organized, how and at what level are decisions on delta management taken?

To address the challenges deltas world-wide face and to facilitate integrated sustainable and resilient management, an integrated approach combining mechanistic knowledge of natural system functioning, comprising interacting physical, chemical, and biological processes, with specialized knowledge on spatial planning, land and water governance and legislative frameworks is required. Such an integrated approach has been lacking to date and forms an interdisciplinary challenge that will be engaged within Future Deltas (Fig. 1).

\section{Research focus}

In Future Deltas we initially focus on problems in deltas related to subsidence and loss of ecosystem services. Both topics include physical, chemical, biological and governance aspects. Our ultimate aim is to generate and integrate knowledge on these two topics and to apply this in the development of coherent conceptual and numerical delta models to predict delta dynamics and inform management and governance. The integrated delta models will provide tools to de- 


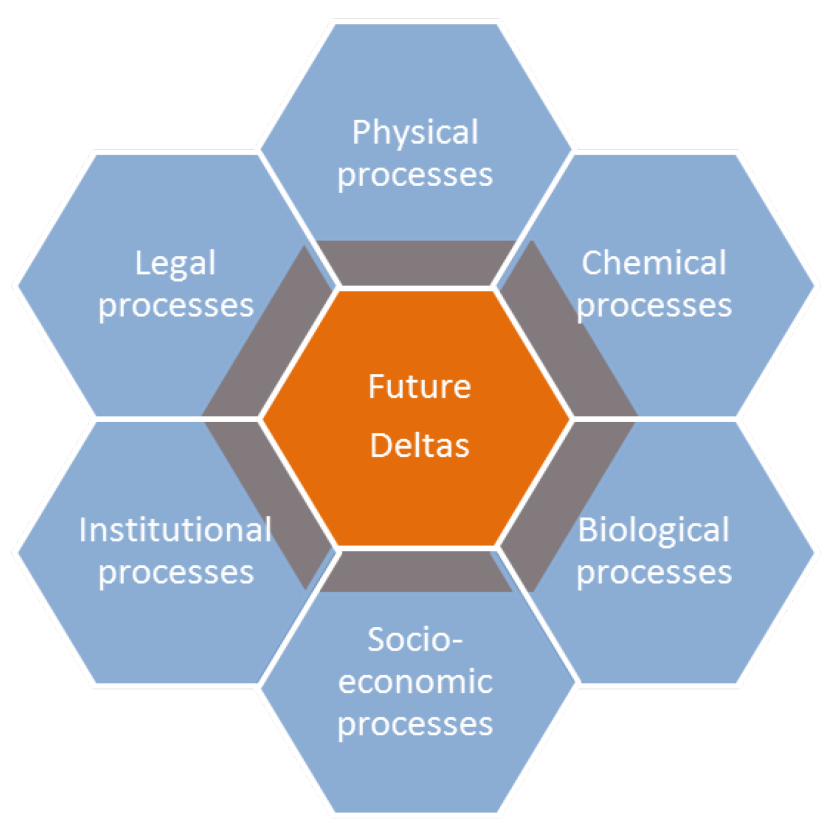

Figure 1. Mono-disciplinary research fields will be integrated in Future Deltas, generating understanding of the functioning of the delta system as a whole, including physical, chemical, biological, socio-economic, institutional and legal processes and their interactions.

sign and evaluate the impact of new, innovative strategies for delta management such as related to subsidence, wetland restoration and the recovery of ecosystem services. On the longer term, we envisage a broadening of the focus area by the inclusion of additional topics that address new emerging priorities.

\subsection{Subsidence}

Although land subsidence poses a far more immediate and severe problem than for instance climate-change-induced sea-level rise (i.e. the rate of subsidence is in many populated deltas worldwide an order of magnitude higher $\left(\mathrm{cm} \mathrm{yr}^{-1}\right)$ than the rate of eustatic (global) sea-level rise $\left(\mathrm{mm} \mathrm{yr}^{-1}\right.$; Church et al., 2013), the processes and consequences of land subsidence have yet to receive the full and integrated scientific and public awareness. Delta subsidence causes a range of problems, including flooding, salt water intrusion, fresh water scarcity, damage to buildings and infrastructure, loss of cultivated land, wetlands and biodiversity, degradation of fishing areas, and rapid shoreline retreat. Combined with a future sea-level rise, submerging of deltaic areas is projected to increase by $50 \%$ by the end of the 21 st century (Syvistki et al., 2009).

\subsection{Ecosystem services}

Mankind relies heavily on deltas and associated water bodies and wetlands for the delivery of essential ecosystem services, including primary production and agriculture, environmental filtering and water quality improvement, flood abatement, coastal protection and safety, nature and biodiversity conservation, and critical interactions with the atmosphere and climate through greenhouse gas reduction and carbon sequestration. It is imperative that provisioning of delta services be included in future planning and governance schemes that integrate ecosystem services into the discussion of land use rights and the governance of limited resources. The knowledge generated within this topic will facilitate adaptation decisions for nature management, biodiversity restoration, water resources management, sustainable agriculture, urban planning, and area developments yielding safer and more resilient delta systems for the future.

\section{Research themes}

Our research is structured into three main themes that are described in the next sections (see also Fig. 2).

\subsection{Understanding drivers}

The scientific challenge of this theme is to understand the complex interactions between physical, biological and chemical processes, and human interventions that affect subsidence and loss of ecosystem services in deltas. There are numerous natural and human-induced drivers of land subsidence. Natural drivers are tectonics, isostasy, and sediment compaction. Human-induced drivers include extraction of groundwater and hydrocarbons, peat oxidation due to artificial groundwater level lowering, loading by buildings and infrastructure, and sediment starvation due to upstream sediment trapping. Human forcing of subsidence is influenced by socio-economic conditions and the governance system.

Subsiding land in deltas potentially affects ecosystem functioning by degradation or loss of agricultural soils, reduced freshwater supply by intrusion of salt water, deterioration of water quality by eutrophication, loss of biodiversity and loss of coastal protection zones. Also, groundwater level lowering in peat soils causes subsidence due to peat oxidation, which leads to considerable greenhouse gas emissions thereby generating a positive feedback on climate change, as the expectations are that climate change will further accelerate peat oxidation and subsidence under prolonged periods of drought and higher temperatures.

In Future Deltas it is our aim to unravel and quantify the different contributors to subsidence in different deltas, and to understand how they relate to loss of ecosystem services under a changing climate. 


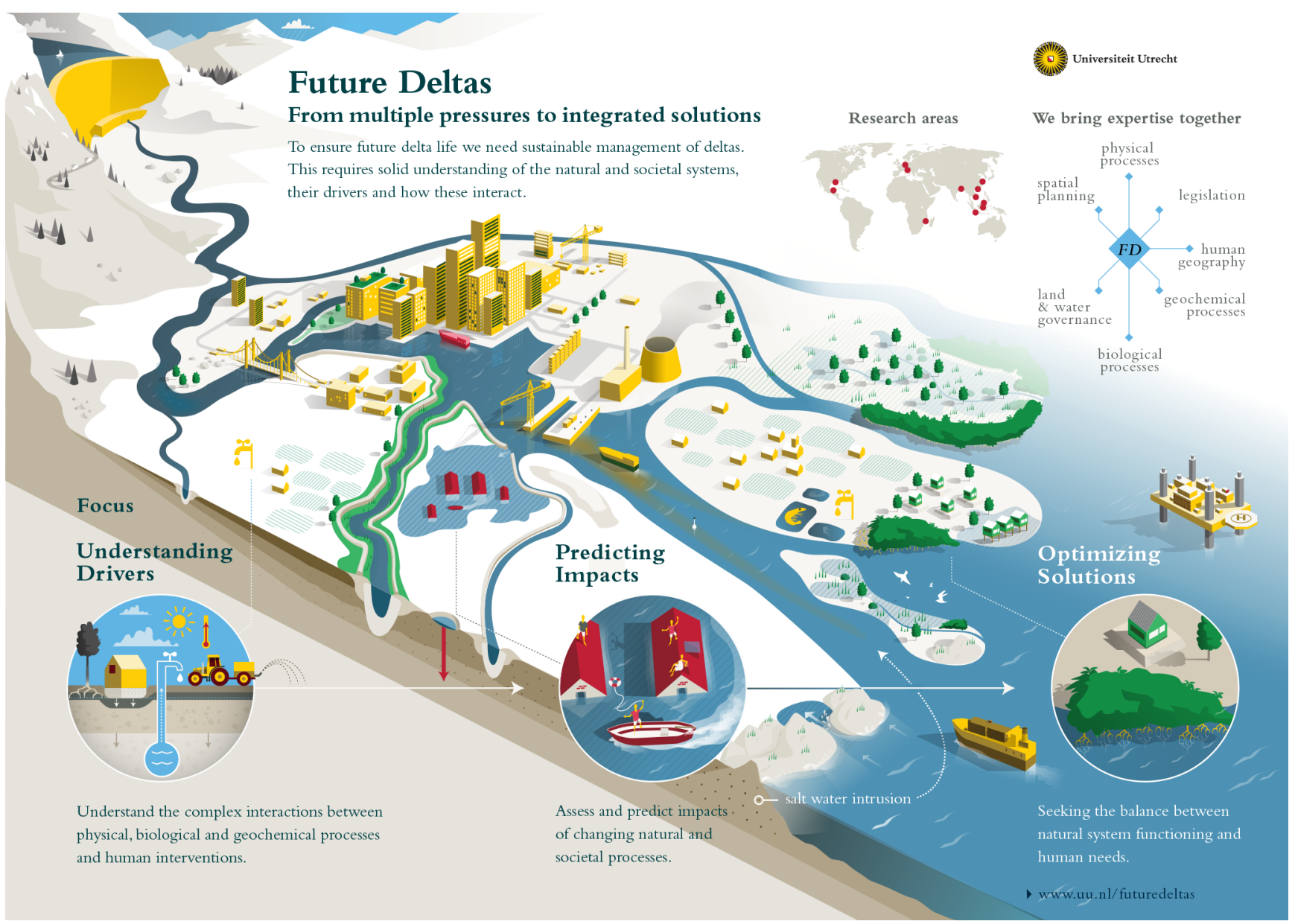

Figure 2. Future Deltas focusses on understanding drivers of change, predicting impacts and optimizing solutions in deltas.

\subsection{Predicting impacts}

The scientific challenge of this theme is to assess and predict impacts of subsidence and loss of ecosystem services in deltas. These impacts not only affect livability in deltas but also potentially reduce a delta's capability to adapt to and recover from external and internal forcing of change. If thresholds are crossed a delta system may collapse, thereby losing its valuable services.

Subsidence has a direct impact on dynamics of water, sediment, nutrients and vegetation, and hence on the boundary conditions of ecosystem functioning. We aim to assess and predict these changing dynamics and their impacts on water security including flood risk, food security, land use and land loss, and on socio-economic and livelihood conditions.

\subsection{Optimizing management solutions}

The scientific challenge of this theme is to analyse, evaluate and optimize strategies to deal with impacts of subsidence and loss of ecosystem services. Sustainable delta management strategies are needed to ensure that future delta so- cieties benefit from vital services provided by deltas while not exhausting or destroying them. Delta managers aiming to restore or mitigate subsidence not only need fundamental knowledge concerning processes that drive changes in deltas and associated impacts, but also must take into account the socio-economic and governance system and legislative frameworks operating in the area.

We evaluate strategies to deal with impacts of subsidence and loss of ecosystem services in deltas as the basis, to improve and optimize delta management. We focus especially on regulatory and policy approaches that support or hamper change in different deltas, awareness building, financing the prevention or restoration of subsidence. We also emphasize issues related to burden sharing and diverse and fragmented public and private responsibilities such as water management, land use, nature conservation, drinking water supply, urban and rural development and agriculture to prevent and restore damages.

Dealing with uncertain risks and shifts in land use towards more sustainable and resilient deltas call for public and private involvement and responsibilities. To address these re- 
sponsibilities in an appropriate and legitimate way, based on shared and mutual responsibilities on different levels and scales and taking equitable burden and benefit sharing as leading principles, it is essential to incorporate scientific knowledge concerning natural processes into policy development, environmental legislation and decision-making.

\section{Further information}

Future Deltas is a close cooperation between the faculties Geosciences, Science and Law, Economics and Governance of Utrecht University. Organisations that are interested in our integrated approach are cordially invited to join the Future Deltas research programme. Further information on Future Deltas can be obtained from Esther Stouthamer (e.stouthamer@uu.nl) and/or from our website www.uu.nl/ futuredeltas.

Acknowledgements. We thank our Future Deltas colleagues that all have contributed to this paper: H. Middelkoop, P. Hoekstra, M. van der Vegt, G. A. Kowalchuk, M. M. Hefting, M. B. Soons, P. P. J. Driessen, F. S. J. van Laerhoven, H. F. M. W. van Rijswick, F. A. G. Groothuijse, E. B. Zoomers, and R. Fletcher.

\section{References}

Church, J. A., Clark, P. U., Cazenave, A., Gregory, J. M., Jevrejeva, S., Levermann, A., Merrifield, M. A., Milne, G. A., Nerem, R. S., Nunn, P. D., Payne, A. J., Pfeffer, W. T., Stammer, D., and Unnikrishnan, A. S.: Sea Level Change, in: Climate Change 2013: The Physical Science Basis, Contribution of Working Group I to the Fifth Assessment Report of the Intergovernmental Panel on Climate Change, edited by: Stocker, T. F., Qin, D., Plattner, G.K., Tignor, M., Allen, S. K., Boschung,J., Nauels, A., Xia, Y., Bex, V., and Midgley, P. M., Cambridge University Press, Cambridge, UK and New York, NY, USA, 2013.

Giosan, L., Syvitski, J. P. M., Constantinescu, S., and Day, J.: Climate change: Protect the world's deltas, Nature, 516, 31-33, 2014.

Syvitski, J. P. M.: Deltas at risk, Sustain. Sci., 3, 23-32, 2008.

Syvitski, J. P. M., Kettner, A. J., Overeem, I., Hutton, E. W. H., Hannon, M. T., Brakenridge, G. R., Day, J., Vörösmarty, C., Saito, Y., Giosan, L., and Nicholls, R. J.: Sinking deltas due to human activities, Nat. Geosci., 2, 681-686, 2009.

Vörösmarty, C. J., Syvitsky, J. P. M., Day, J., de Sherbinin, A., Giosan, L., and Paola, C.: Battling to save the world's river deltas, B. Atom. Sci., 65, 31-43, 2009. 